\section{(6) OPEN ACCESS}

\title{
Effectiveness of influenza vaccination in working-age adults with diabetes: a population-based cohort study
}

\author{
Darren Lau, ${ }^{1}$ Dean T Eurich, ${ }^{1}$ Sumit R Majumdar, ${ }^{1,2}$ Alan Katz, ${ }^{3}$ Jeffrey A Johnson ${ }^{1}$
}

\begin{abstract}
- Additional material is published online only. To view please visit the journal online (http://dx.doi.org/10.1136/ thoraxjnl-2012-203109).

${ }^{1}$ Department of Public Health Sciences, University of Alberta, Edmonton, Canada

${ }^{2}$ Faculty of Medicine and Dentistry, University of Alberta, Edmonton, Canada

${ }^{3}$ Department of Community Health Sciences, University of Manitoba, Winnipeg, Canada
\end{abstract}

\section{Correspondence to}

Dr Jeffrey A Johnson, 2-040G Li Ka Shing Center for Health Research Innovation, 8602112 Street, Department of Public Health Sciences, University of Alberta, Edmonton, Canada, AB T6G 2E1:

jeff.johnson@ualberta.ca

Received 7 December 2012 Revised 7 February 2013 Accepted 2 March 2013 Published Online First 27 March 2013

\section{ABSTRACT \\ Background Guidelines recommend influenza} vaccinations in all diabetic adults, but there is limited evidence to support vaccinating working-age adults ( $<65$ years) with diabetes. We examined the effectiveness of influenza vaccine in this subgroup, compared with elderly adults ( $\geq 65$ years) for whom vaccination recommendations are well accepted.

Methods We identified all adults with diabetes, along with a sample of age-matched and sex-matched comparison subjects without diabetes, from 2000 to 2008, using administrative data from Manitoba, Canada. With multivariable Poisson regression, we estimated vaccine effectiveness (VE) on influenza-like illnesses (ILIS), pneumonia and influenza (PI) hospitalisations and all-cause (ALL) hospitalisations during periods of known circulating influenza. Analyses were replicated outside of influenza season to rule out residual confounding.

Results We included 543367 person-years of followup, during which $223920 \mathrm{ILI}, 5422 \mathrm{PI}$ and $94988 \mathrm{ALL}$ occurred. The majority $(58 \%)$ of adults with diabetes were working age. In this group, influenza vaccination was associated with relative reductions in $\mathrm{Pl}(43 \%, 95 \%$ $\mathrm{Cl} 28 \%$ to $54 \%)$ and $\mathrm{ALL}(28 \%, 95 \% \mathrm{Cl} 24 \%$ to $32 \%)$ but not ILI $(-1 \%, 95 \% \mathrm{Cl}-3 \%$ to $1 \%)$. VE was similar in elderly adults for ALL (33-34\%) and PI (45-55\%), although not ILI (12-13\%). However, similar estimates of effectiveness were also observed for all three groups during non-influenza control periods.

Conclusions Working-age adults with diabetes experience similar benefits from vaccination as elderly adults, supporting current diabetes-specific recommendations. However, these benefits were also manifest outside of influenza season, suggesting residual bias. Vaccination recommendations in all high-risk adults would benefit from randomised trial evidence.

\section{INTRODUCTION}

Influenza is a common acute respiratory infection, which typically circulates during the winter-spring months of the year. Morbidity and mortality due to influenza are substantial and concentrated in certain high-risk groups, ${ }^{1-3}$ including adults with diabetes. ${ }^{4}$ Although studies concerning the sequelae of influenza infection in those with diabetes are sparse, clinical practice guidelines recommend targeted vaccination against influenza in all adults with diabetes. ${ }^{5} 5$ Even US guidelines, which advocate the universal vaccination of all adults, prioritise those with diabetes. ${ }^{3}$ Since recommendations for universal vaccination of the elderly

\section{Key messages}

What is the key question?

- Do working-age adults with diabetes experience benefit from influenza vaccine similar to that of elderly adults, in whom recommendations for routine vaccination are well accepted?

\section{What is the bottom line?}

- In working-age diabetic adults and elderly adults alike, influenza vaccinations appeared to reduce hospitalisations during influenza season, as well as outside of influenza season.

\section{Why read on?}

- Inlfuenza vaccination guidelines targeting diabetic adults are based on flawed observational evidence and would benefit from randomised trials.

$\left(\geq 65\right.$ years) ${ }^{2}{ }^{3}$ are already well accepted, ${ }^{7} 8$ these guidelines effectively single out working-age adults ( $<65$ years) with diabetes for vaccination.

Four observational studies have examined the effectiveness of influenza vaccinations in adults with diabetes. $^{9-12}$ Hak et al and Heymann et al examined vaccine effectiveness (VE) in elderly diabetic adults and found evidence of benefit consistent with those of previous observational studies in elderly adults generally. ${ }^{13}{ }^{14}$ Only two of these studies, both casecontrol designs, involved working-age adults. Colquhoun et $a l^{11}$ and Looijmans-Van Den Akker et $a l^{12}$ reported vaccination-associated reductions in hospitalisations of $70-79 \%$ in working-age adults with diabetes. However, their composite outcomes, composed mostly of acute complications of diabetes, did not capture more common influenza complications or outpatient visits. Moreover, neither study assessed unmeasured confounding by examining VE during control periods outside of influenza season. ${ }^{15}$

Thus, we examined the effectiveness of influenza vaccine for reducing influenza-like illness (ILI), pneumonia and influenza (PI) hospitalisations and allcause (ALL) hospitalisations. Working-age adults ( $<65$ years) with diabetes comprised our population of primary interest. Elderly adults ( $\geq 65$ years) irrespective of diabetes were chosen as reference groups for comparison, since vaccinations in elderly adults 
are universally accepted. ${ }^{78}$ Additionally, outcomes in adults with diabetes may be comparable with those of non-diabetic adults approximately 10 years older. ${ }^{16}$ In particular, the rate of influenza-attributable hospitalisations in non-elderly adults with diabetes ${ }^{17}$ is similar to that of elderly adults. ${ }^{18}{ }^{19}$ We included offseason control periods to assess the extent of residual confounding related to the 'healthy vaccinee effect' in studies of VE. ${ }^{20}$

\section{METHODS}

We performed a population-based cohort study using administrative data from Manitoba, Canada. Nearly all residents receive healthcare benefits under Manitoba's system of universal healthcare insurance. The administrative databases of Manitoba Health capture basic demographic data, diagnoses and procedures provided during community physician visits and hospital admissions and pharmaceuticals dispensed at the point of sale. ${ }^{21}$ Additionally, the Manitoba Immunization Monitoring System records influenza and pneumococcal vaccinations provided by physicians and public health clinics in the community. ${ }^{22}$ These databases are housed at the Manitoba Centre for Health Policy. This study was approved by the Health Research Ethics Boards of the University of Alberta and the University of Manitoba and by the Health Information and Privacy Committee of Manitoba.

We identified all working-age adults ( $\geq 18$ and $<65$ years) with diabetes from 1 July 2000 to 30 June 2008. Diabetes was defined as two ambulatory physician claims or one hospital discharge for diabetes (ICD-9 code 250 or ICD-10 codes E10-E11). ${ }^{23}$ To compose our reference groups, we additionally identified all elderly adults ( $\geq 65$ years) with diabetes, who were each matched with up to two non-diabetic adults on the basis of age, sex and residence. We thus estimated influenza VE for three distinct groups: working-age diabetic adults, our primary group of interest, versus elderly adults with and without diabetes.

We divided calendar time into years from July 1 to June $30 .{ }^{17}$ Influenza season was defined as a continuous period between the first and last occurrences of at least two consecutive weeks with two or more ILI isolates positive for influenza, according to provincial surveillance data. ${ }^{24}$ We partitioned off-season time into two discrete periods: a preseason period from October 1 to the beginning of influenza season and a postseason period from the end of influenza season until June 30 each year. ${ }^{15}$

Subjects were followed until 30 June 2008, for any occurrences of three outcomes, based on ICD diagnostic codes: physician visits or hospitalisations for ILI, PI hospitalisations and ALL hospitalisations. ILI consisted of a broad bundle of diagnoses, including bronchitis, pneumonia, cold, cough, exacerbations of chronic obstructive pulmonary disease (COPD), pharyngitis and sinusitis (see online supplementary material). Our definition of ILI was determined by a pilot study in Edmonton, Alberta, and is similar to other definitions showing strong correlations with seasonal influenza activity. ${ }^{25}{ }^{26}$ A sensitivity analysis excluding pharyngitis and sinusitis was performed and yielded practically identical results (see online supplementary material). ILI was chosen to represent the common manifestations of influenza, PI hospitalisations to depict more serious and specific respiratory sequelae and ALL hospitalisations to indicate the potential overall burden of influenza on serious morbidity and mortality.

We fitted logistic regression models to examine the predictors of influenza vaccination each year. Potential predictors were diabetes status, age, sex, urban or rural residence, socioeconomic status (SES), comorbid health status and number of physician visits in the previous year. SES was based on the census-derived income quintile of each subject's postal code area of residence. ${ }^{27}$

Table 1 Characteristics of included person-time

\begin{tabular}{|c|c|c|c|c|c|c|c|}
\hline \multirow[b]{2}{*}{ Variable } & \multirow[b]{2}{*}{ Value } & \multicolumn{2}{|c|}{$\begin{array}{l}\text { Working age } \\
\text { Diabetes }\end{array}$} & \multicolumn{2}{|l|}{$\begin{array}{l}\text { Elderly } \\
\text { Diabetes }\end{array}$} & \multicolumn{2}{|c|}{$\begin{array}{l}\text { No diabetes (matched } \\
\text { controls) }\end{array}$} \\
\hline & & $\mathrm{N}$ & $\mathbf{P}$ & $\mathrm{N}$ & $\mathbf{P}$ & $\mathrm{N}$ & $\mathbf{P}$ \\
\hline Age (median, IQR) & Years & 53 & 13.00 & 74 & 11.00 & 74 & 11.00 \\
\hline Sex & $\begin{array}{l}\text { Male } \\
\text { Female }\end{array}$ & $\begin{array}{l}129638 \\
119473\end{array}$ & $\begin{array}{l}0.52 \\
0.48\end{array}$ & $\begin{array}{l}84895 \\
95020\end{array}$ & $\begin{array}{l}0.47 \\
0.53\end{array}$ & $\begin{array}{l}127211 \\
161076\end{array}$ & $\begin{array}{l}0.44 \\
0.56\end{array}$ \\
\hline Income quintile & $\begin{array}{l}\text { Upper } \\
\text { Lower }\end{array}$ & $\begin{array}{l}111167 \\
137944\end{array}$ & $\begin{array}{l}0.45 \\
0.55\end{array}$ & $\begin{array}{r}77806 \\
102109\end{array}$ & $\begin{array}{l}0.43 \\
0.57\end{array}$ & $\begin{array}{l}137303 \\
150984\end{array}$ & $\begin{array}{l}0.48 \\
0.52\end{array}$ \\
\hline Residence & $\begin{array}{l}\text { Urban } \\
\text { Rural }\end{array}$ & $\begin{array}{l}145712 \\
103399\end{array}$ & $\begin{array}{l}0.58 \\
0.42\end{array}$ & $\begin{array}{r}108147 \\
71768\end{array}$ & $\begin{array}{l}0.60 \\
0.40\end{array}$ & $\begin{array}{l}173204 \\
115083\end{array}$ & $\begin{array}{l}0.60 \\
0.40\end{array}$ \\
\hline Medical visits* & $\begin{array}{l}0 \\
1-2 \\
3 \text { or more }\end{array}$ & $\begin{array}{r}145564 \\
62666 \\
40881\end{array}$ & $\begin{array}{l}0.58 \\
0.25 \\
0.16\end{array}$ & $\begin{array}{l}92265 \\
42034 \\
45616\end{array}$ & $\begin{array}{l}0.51 \\
0.23 \\
0.25\end{array}$ & $\begin{array}{r}174940 \\
60511 \\
52836\end{array}$ & $\begin{array}{l}0.61 \\
0.21 \\
0.18\end{array}$ \\
\hline Major ADGst & $\begin{array}{l}0 \\
1 \\
2 \text { or more }\end{array}$ & $\begin{array}{r}109107 \\
74930 \\
65074\end{array}$ & $\begin{array}{l}0.44 \\
0.30 \\
0.26\end{array}$ & $\begin{array}{l}46630 \\
55893 \\
77392\end{array}$ & $\begin{array}{l}0.26 \\
0.31 \\
0.43\end{array}$ & $\begin{array}{r}102347 \\
92029 \\
93911\end{array}$ & $\begin{array}{l}0.36 \\
0.32 \\
0.33\end{array}$ \\
\hline Influenza vaccination $\ddagger$ & $\begin{array}{l}\text { Yes } \\
\text { No }\end{array}$ & $\begin{array}{r}86222 \\
162889\end{array}$ & $\begin{array}{l}0.35 \\
0.65\end{array}$ & $\begin{array}{l}96463 \\
83452\end{array}$ & $\begin{array}{l}0.54 \\
0.46\end{array}$ & $\begin{array}{l}139114 \\
149173\end{array}$ & $\begin{array}{l}0.48 \\
0.52\end{array}$ \\
\hline Pneumococcal vaccination§ & $\begin{array}{l}\text { Yes } \\
\text { No }\end{array}$ & $\begin{array}{r}40020 \\
209091\end{array}$ & $\begin{array}{l}0.16 \\
0.84\end{array}$ & $\begin{array}{l}82084 \\
97831\end{array}$ & $\begin{array}{l}0.46 \\
0.54\end{array}$ & $\begin{array}{l}116178 \\
172109\end{array}$ & $\begin{array}{l}0.40 \\
0.60\end{array}$ \\
\hline
\end{tabular}


Table 2 Included person-years and events

\begin{tabular}{llllll}
\hline & & & \multicolumn{3}{c}{ Number of outcomes* } \\
\cline { 5 - 6 } Diabetes & Period & N (PY) & ILI & PI & ALL \\
\hline Working age & & & & & \\
diabetes & PRE & 70415 & 33518 & 387 & 7584 \\
& INS & 70380 & 38804 & 487 & 7829 \\
& POST & 54504 & 21842 & 236 & 5683 \\
Elderly & & & & & \\
$\quad$ diabetes & PRE & 49877 & 20569 & 775 & 14326 \\
& INS & 50308 & 23008 & 953 & 14945 \\
& POST & 38421 & 13598 & 550 & 10928 \\
No diabetes & PRE & 77347 & 27376 & 725 & 12374 \\
(matched controls) & INS & 76233 & 28499 & 815 & 12679 \\
& POST & 55881 & 16706 & 494 & 8640 \\
\hline
\end{tabular}

*Outcomes: ALL, all-cause hospitalisations; ILI, influenza-like illness; PI, pneumonia and influenza hospitalisations.

INS, Influenza season; POST, Post-season period from the end of influenza season until June 30 each year; PRE, Pre-season period from October to the beginning of influenza season.

Comorbid health status was represented using two adjusted diagnostic group (ADG)-based variables: one indicating the number of major ADGs and another indicating the number of minor ADGs, accrued in the previous 2 years. ${ }^{22} 28$ Covariates were updated every July 1.

We then fitted Poisson regression models describing the incidence rates of each outcome as a function of influenza vaccination status. The resulting incidence rate ratios (IRRs) were used to estimate vaccine effectiveness ( $\mathrm{VE}=1-\mathrm{IRR})$. Time-varying analyses were performed, with each subject's follow-up time split into vaccinated and unvaccinated weeks. Models included follow-up time in person-years as an offset term. In addition to the above predictors, models included pneumococcal vaccination status and dummy variables for each month and each year as covariates. VE was estimated for influenza season and for the two off-season periods. Because influenza circulation is minimal during the offseason, any apparent effect of influenza vaccine on outcomes during these periods suggests bias. ${ }^{15}$ Analyses were performed using SAS V.9.2 (SAS Institute Inc, Cary, North Carolina, USA).

\section{RESULTS}

We identified 99781 adults with diabetes in Manitoba from 2000 to 2008. After matching, our analytic cohort was composed of 91605 diabetic adults. Of these, 56513 (58\%) were working-age adults with diabetes. Included subjects contributed 543367 person-years of follow-up. Working-age adults with diabetes were generally healthier, although less likely to have received influenza or pneumococcal vaccinations than elderly adults (table 1). On average, 31139 working-age adults with diabetes were followed each year, representing approximately $3 \%$ of the entire Manitoba population. Included subjects contributed 223920 ILI, 5422 PI hospitalisations and 94988 ALL hospitalisations (table 2).

\section{Predictors of vaccination status}

Vaccination rates ranged from $35 \%$ in working-age adults with diabetes to $51-56 \%$ in elderly adults without and with diabetes, respectively. Increasing age, female sex, diabetes and better SES were each significantly associated with greater odds of vaccination (table 3). In contrast, poorer health status, indicated by increasing numbers of major ADGs and medical visits, was associated with increased vaccinations in working-age adults, but decreased vaccination odds in the elderly (table 3 ). These trends were similar regardless of diabetes status.

\section{VE during influenza season}

In working-age adults with diabetes, influenza vaccine had no apparent effect on ILI $(\mathrm{VE}=1 \%, 95 \%$ CI $-1 \%$ to $3 \%$; $\mathrm{p}=0.402)$ but was associated with $43 \%(95 \%$ CI $28 \%$ to $54 \%$; $\mathrm{p}<0.001)$ and $28 \%(95 \%$ CI $24 \%$ to $32 \% ; \mathrm{p}<0.001)$ decreases in PI and ALL hospitalisations, respectively (table 4). In elderly adults, influenza vaccine was similarly effective against all outcomes $\quad(\mathrm{VE}-\mathrm{ILI}=12-13 \%, \quad \mathrm{PI}=45-55 \%, \quad$ ALL $=33-34 \%)$, regardless of diabetes status. Compared with elderly adults, influenza vaccine in working-age adults with diabetes was associated with broadly similar reductions in PI and ALL hospitalisations but no reduction in ILI (figure 1).

Table 3 Predictors of vaccination status in elderly and working-age adults with and without diabetes

\begin{tabular}{|c|c|c|c|c|c|c|c|}
\hline \multirow[b]{2}{*}{ Variable } & \multirow[b]{2}{*}{ Value } & \multicolumn{2}{|c|}{$\begin{array}{l}\text { Working age } \\
\text { Diabetes }\end{array}$} & \multicolumn{2}{|c|}{$\begin{array}{l}\text { Elderly } \\
\text { Diabetes }\end{array}$} & \multicolumn{2}{|c|}{$\begin{array}{l}\text { No diabetes (matched } \\
\text { controls) }\end{array}$} \\
\hline & & OR & $95 \% \mathrm{Cl}$ & OR & $95 \% \mathrm{Cl}$ & OR & $95 \% \mathrm{Cl}$ \\
\hline Sex & Female & 1.36 & (1.34 to 1.38 ) & 1.03 & $(1.01,1.05)$ & 1.14 & (1.12 to 1.16$)$ \\
\hline Age & $\begin{array}{l}18-25 \text { years } \\
26-45 \text { years } \\
46-65 \text { years } \\
66-85 \text { years } \\
86+\text { years }\end{array}$ & $\begin{array}{l}\text { Ref. } \\
1.63 \\
3.24 \\
- \\
-\end{array}$ & $\begin{array}{l}\text { Ref. } \\
\text { (1.51 to } 1.77) \\
\text { (3.00 to } 3.51) \\
- \\
-\end{array}$ & $\begin{array}{l}- \\
- \\
- \\
\text { Ref. } \\
0.69\end{array}$ & $\begin{array}{l}- \\
- \\
- \\
\text { Ref. } \\
\text { (0.67 to } 0.71 \text { ) }\end{array}$ & $\begin{array}{l}- \\
- \\
- \\
\text { Ref. } \\
0.72\end{array}$ & $\begin{array}{l}- \\
- \\
- \\
\text { Ref. } \\
(0.70 \text { to } 0.74)\end{array}$ \\
\hline Income & Upper & 1.25 & (1.23 to 1.27$)$ & 1.23 & (1.21 to 1.26$)$ & 1.17 & (1.15 to 1.19$)$ \\
\hline Residence & Urban & 1.34 & (1.31 to 1.36$)$ & 1.31 & (1.29 to 1.34$)$ & 1.15 & (1.13 to 1.17$)$ \\
\hline Minor ADGs & $\begin{array}{l}2-3 \\
4 \text { or more }\end{array}$ & $\begin{array}{l}1.58 \\
2.17\end{array}$ & $\begin{array}{l}\text { (1.50 to } 1.67) \\
\text { (2.06 to } 2.28)\end{array}$ & $\begin{array}{l}1.78 \\
2.50\end{array}$ & $\begin{array}{l}(1.66 \text { to } 1.90) \\
(2.35 \text { to } 2.67)\end{array}$ & $\begin{array}{l}3.57 \\
5.77\end{array}$ & $\begin{array}{l}\text { (3.44 to } 3.71) \\
\text { (5.57 to } 5.98)\end{array}$ \\
\hline Major ADGs & $\begin{array}{l}1 \\
2 \text { or more }\end{array}$ & $\begin{array}{l}1.14 \\
1.15\end{array}$ & $\begin{array}{l}\text { (1.11 to } 1.16) \\
(1.13 \text { to } 1.18)\end{array}$ & $\begin{array}{l}1.02 \\
0.78\end{array}$ & $\begin{array}{l}(0.99 \text { to } 1.04) \\
(0.76 \text { to } 0.80)\end{array}$ & $\begin{array}{l}1.15 \\
0.94\end{array}$ & $\begin{array}{l}(1.13 \text { to } 1.17) \\
(0.92 \text { to } 0.96)\end{array}$ \\
\hline Medical visits & $\begin{array}{l}2-3 \\
4 \text { or more }\end{array}$ & $\begin{array}{l}1.17 \\
1.23\end{array}$ & $\begin{array}{l}\text { (1.14 to } 1.20) \\
(1.19 \text { to } 1.26)\end{array}$ & $\begin{array}{l}1.05 \\
0.85\end{array}$ & $\begin{array}{l}(1.02 \text { to } 1.08) \\
(0.83 \text { to } 0.87)\end{array}$ & $\begin{array}{l}1.08 \\
0.97\end{array}$ & $\begin{array}{l}(1.05 \text { to } 1.11) \\
(0.95 \text { to } 1.00)\end{array}$ \\
\hline
\end{tabular}

All $p$ values $<0.001$. Reference groups: Sex (male), age (18-25 or 66-85 years), income (below median), residence (rural), minor ADGs (0-1 ADGs), major ADGs (0 ADGs), medical visits (0-1 visits). ADGs cumulated over the previous 2 years. Medical visits cumulated over the previous year. 
Table 4 Adjusted associations between influenza vaccination status and outcomes during influenza season

\begin{tabular}{|c|c|c|c|c|c|c|c|c|c|c|}
\hline \multirow[b]{2}{*}{ Age group } & \multirow[b]{2}{*}{ Diabetes } & \multicolumn{3}{|l|}{ ILI } & \multicolumn{3}{|c|}{ PI hospitalisations } & \multicolumn{3}{|c|}{ ALL hospitalisations } \\
\hline & & IRR* & $\mathrm{Cl}$ & p Value & IRR & $\mathrm{Cl}$ & p Value & IRR & $\mathrm{Cl}$ & p Value \\
\hline Working age & DM & 0.99 & (0.97 to 1.01$)$ & 0.402 & 0.57 & (0.46 to 0.72 ) & 0.000 & 0.72 & (0.68 to 0.76$)$ & 0.000 \\
\hline Elderly & $\begin{array}{l}\text { DM } \\
\text { No DM }\end{array}$ & $\begin{array}{l}0.87 \\
0.88\end{array}$ & $\begin{array}{l}(0.84 \text { to } 0.90) \\
(0.85 \text { to } 0.90)\end{array}$ & $\begin{array}{l}0.000 \\
0.000\end{array}$ & $\begin{array}{l}0.55 \\
0.45\end{array}$ & $\begin{array}{l}(0.47 \text { to } 0.66) \\
(0.37 \text { to } 0.55)\end{array}$ & $\begin{array}{l}0.000 \\
0.000\end{array}$ & $\begin{array}{l}0.67 \\
0.66\end{array}$ & $\begin{array}{l}(0.64 \text { to } 0.70) \\
(0.63 \text { to } 0.69)\end{array}$ & $\begin{array}{l}0.000 \\
0.000\end{array}$ \\
\hline
\end{tabular}

\section{VE during off-season periods}

In working-age adults with diabetes, influenza vaccine reduced ALL hospitalisations by $22-31 \%$ outside of influenza season (table 5, figure 2). Additionally, VE point estimates were suggestive of reduced PI hospitalisations during the postseason period (postseason $\mathrm{VE}=24 \%, 95 \% \mathrm{CI}-4 \%$ to $45 \%$; $\mathrm{p}=0.085$ ). In a similar manner, influenza vaccine was associated with reductions each of ILI (7-29\%), PI hospitalisations (39-61\%) and ALL hospitalisations (30-40\%) during pre-influenza and post-influenza season periods, among elderly adults (table 5).

\section{DISCUSSION}

In a study of more than 50000 working-age adults with diabetes, influenza vaccine was associated with a $43 \%$ reduction in PI hospitalisations and a $28 \%$ reduction in ALL hospitalisations. Similar estimates of VE were observed in elderly adults, a group for whom vaccination guidelines are generally well accepted. Thus, using conventional analytic approaches, our study provides evidence supporting vaccination in working-age adults with diabetes of a degree similar to that in the elderly. ${ }^{13}$ However, a vaccine-attributable reduction in outcomes was also observed during off-season time, suggesting residual confounding.

Guidelines recommending vaccinations in elderly adults are well accepted by primary care clinicians and public health professionals, as physician surveys ${ }^{7}$ and the impressive commitment of resources to vaccination campaigns each year ${ }^{29}$ attest. The general enthusiasm for vaccination is based on evidence of

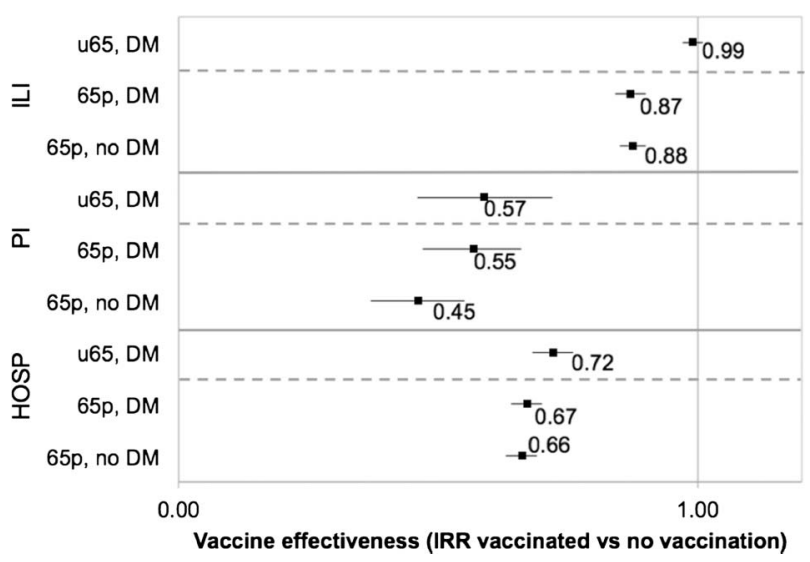

Figure 1 Estimates of influenza vaccine effectiveness during influenza season. Error bars represent $95 \%$ Cls. 65p, elderly (ie, 65 plus); $65 p$, DM, elderly adults with diabetes mellitus; $65 p$, no DM, elderly adults without diabetes mellitus; ALL, all-cause hospitalisations; ILI, outpatient visits and hospitalisations for influenza-like illness; PI, pneumonia and influenza hospitalisations; u65, working age; u65, DM, working-age adults with diabetes mellitus. substantial benefits derived primarily from observational studies of elderly adults. ${ }^{13}$ Using similar methods, we obtained similar benefits of vaccination in working-age adults with diabetes. Thus, our study provides relative support for the inclusion of diabetes as a separate indication for influenza vaccination in the guidelines promulgated by the American and Canadian Diabetes Associations, ${ }^{5} 6$ as well as national public health authorities. $^{2} 3$

However, there is also increasing skepticism of the large reductions, particularly in ALL mortality, associated with influenza vaccination in elderly adults. ${ }^{15} 3031$ Our data may be alternatively interpreted as indicating healthy vaccinee bias in diabetic and elderly adults alike. ${ }^{15}$ We observed positive estimates of VE before and after influenza season, when influenza circulation was minimal. One possible explanation is that vaccinated individuals were healthier and more health seeking than their unvaccinated counterparts, quite apart from their vaccination status. ${ }^{20}$ Previous studies have documented the pervasive effects contributed by this 'healthy vaccinee bias ${ }^{20}$ in observational studies of elderly adults. ${ }^{15} 3132$ Our results provide further evidence that such bias is refractory to conventional analytic techniques and suggest that the healthy vaccinee effect may apply similarly to non-elderly adults with high-risk indications.

For PI hospitalisations and ALL hospitalisations, estimates of VE appeared greater after influenza season, compared with the period preceding the onset of circulating influenza. The extent of health vaccinee bias may vary throughout the year as sicker individuals who are less likely to be vaccinated are depleted from the population (eg, through mortality). ${ }^{15}$ However, this would lead to greater estimates of apparent VE before, as opposed to after, influenza season. Although the population dynamics underpinning preseason-postseason variations in our findings remain unclear, the presence of any VE, when influenza is not circulating, is a signal that bias is present.

Two previous case-control studies have reported 70-79\% reductions in composite hospital admissions associated with influenza vaccination in working-age adults with diabetes. ${ }^{11} 12$ These estimates appear unreasonable, since the proportion of hospitalisations actually caused by influenza is unlikely to be as high. ${ }^{19}$ Our own estimates of effectiveness against PI hospitalisations and ALL hospitalisations were substantially lower, although still subject to residual confounding. Randomised trials may be required to produce definitive estimates of VE. ${ }^{31} 33$

Our study has several major limitations. First, we lacked detailed clinical data, such as smoking, glycaemic control or functional status. ${ }^{3132}$ Second, we were unable to measure influenza infection directly. The use of non-specific surrogates for influenza may have attenuated estimates of VE while concomitantly increasing their vulnerability to healthy vaccinee bias. ${ }^{20}$ Third, we did not consider the extent of match or mismatch between circulating viral strains and those included in the 
Table 5 Adjusted associations between influenza vaccination status and outcomes before and after influenza season

\begin{tabular}{|c|c|c|c|c|c|c|c|c|c|c|c|}
\hline \multirow[b]{2}{*}{ Period } & \multirow[b]{2}{*}{ Age group } & \multirow[b]{2}{*}{ Diabetes } & \multicolumn{3}{|l|}{ ILI } & \multicolumn{3}{|c|}{ PI hospitalisations } & \multicolumn{3}{|c|}{ ALL hospitalisations } \\
\hline & & & $\mathrm{IRR}^{*}$ & $\mathrm{Cl}$ & $\mathrm{p}$ Value & IRR & $\mathrm{Cl}$ & $\mathrm{p}$ Value & IRR & $\mathrm{Cl}$ & $p$ Value \\
\hline PRE & $\begin{array}{l}\text { Working age } \\
\text { Elderly }\end{array}$ & $\begin{array}{l}\text { DM } \\
\text { DM } \\
\text { No DM }\end{array}$ & $\begin{array}{l}0.95 \\
0.76 \\
0.71\end{array}$ & $\begin{array}{l}(0.92 \text { to } 0.98) \\
(0.73 \text { to } 0.79) \\
\text { (0.69 to } 0.74)\end{array}$ & $\begin{array}{l}0.000 \\
0.000 \\
0.000\end{array}$ & $\begin{array}{l}0.99 \\
0.58 \\
0.61\end{array}$ & $\begin{array}{l}(0.76 \text { to } 1.28) \\
(0.47 \text { to } 0.72) \\
\text { (0.49 to } 0.77)\end{array}$ & $\begin{array}{l}0.939 \\
0.000 \\
0.000\end{array}$ & $\begin{array}{l}0.78 \\
0.70 \\
0.65\end{array}$ & $\begin{array}{l}(0.73 \text { to } 0.83) \\
(0.67 \text { to } 0.74) \\
\text { (0.62 to } 0.68)\end{array}$ & $\begin{array}{l}0.000 \\
0.000 \\
0.000\end{array}$ \\
\hline POST & $\begin{array}{l}\text { Working age } \\
\text { Elderly }\end{array}$ & $\begin{array}{l}\text { DM } \\
\text { DM } \\
\text { No DM }\end{array}$ & $\begin{array}{l}1.06 \\
0.89 \\
0.93\end{array}$ & $\begin{array}{l}(1.03 \text { to } 1.09) \\
(0.85 \text { to } 0.93) \\
(0.89 \text { to } 0.97)\end{array}$ & $\begin{array}{l}0.000 \\
0.000 \\
0.000\end{array}$ & $\begin{array}{l}0.76 \\
0.39 \\
0.48\end{array}$ & $\begin{array}{l}(0.55 \text { to } 1.04) \\
(0.31 \text { to } 0.50) \\
\text { (0.36 to } 0.62)\end{array}$ & $\begin{array}{l}0.085 \\
0.000 \\
0.000\end{array}$ & $\begin{array}{l}0.69 \\
0.62 \\
0.60\end{array}$ & $\begin{array}{l}(0.65 \text { to } 0.74) \\
(0.59 \text { to } 0.65) \\
(0.57 \text { to } 0.64)\end{array}$ & $\begin{array}{l}0.000 \\
0.000 \\
0.000\end{array}$ \\
\hline
\end{tabular}

*IRR, incidence rate ratio (vaccinated vs not vaccinated), adjusted for sex, age (20-year age bands), income (upper vs lower), pneumococcal vaccination receipt, number of medical visits in the previous year, number of minor ADGs in the previous 2 years, number of major $A D G s$ in the previous 2 years, month and year. $p=0.000$ refers to $p<0.001$.

ALL, All-cause hospitalisations; DM, Diabetes mellitus; ILI, Influenza-like illness; PI, Pneumonia and influenza hospitalizations; POST, Post-season period from the end of influenza season until June 30 each year; PRE, Pre-season period from October to the beginning of influenza season.

influenza vaccine. Restriction to a mismatched period is an alternative means of demonstrating bias. Finally, because our study was conducted in a single province with comprehensive and universal healthcare coverage, our findings may not be widely generalisable.

In our study, influenza vaccine was associated with reductions in PI hospitalisations $(\mathrm{VE}=43-55 \%)$ and ALL hospitalisations $(28-34 \%)$ in all groups during influenza season. These findings, showing a similar benefit from a level of evidence similar to that of well-accepted vaccination guidelines in elderly adults, support guidelines singling out diabetes as a high-risk indication for vaccination to at least the same extent. However, our data also indicated VE during the off-season, suggesting that we, along with many others, ${ }^{9-12} 1430$ have almost certainly overestimated the benefits of vaccination. Thus, the extent to which current vaccination guidelines are justified remains uncertain. We believe that the current evidence is insufficient to promote diabetes as a high-risk indication for influenza vaccination in working-age adults. Vaccinations in working-age adults may be warranted generally, based on randomised trial evidence of modest protection against the symptoms, although not the complications, of influenza. ${ }^{34}$ While additional clinical data and analytic innovation may help improve observational estimates of influenza VE

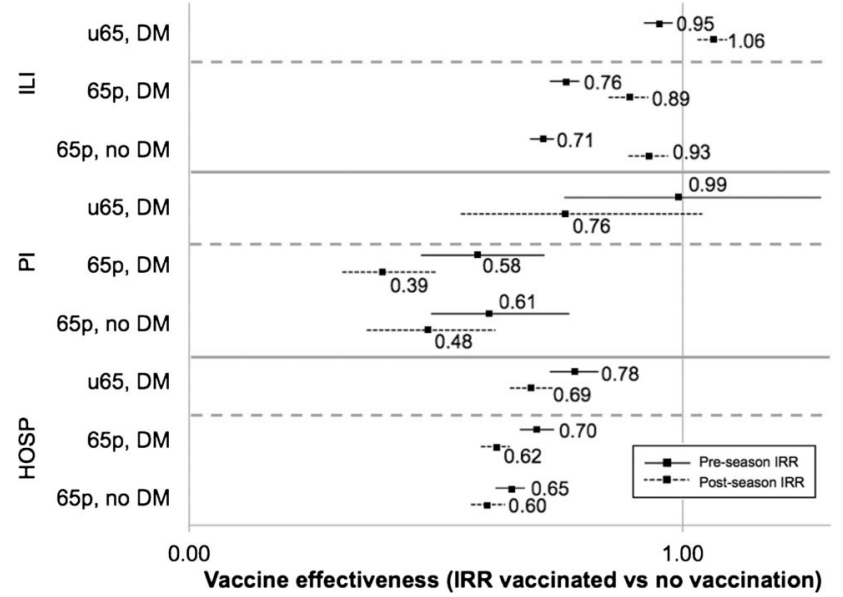

Figure 2 Estimates of influenza vaccine effectiveness during the off-season periods. Error bars represent $95 \%$ Cls. 65p, elderly (ie, 65 plus); 65p, DM, elderly adults with diabetes mellitus; ALL, all-cause hospitalisations; ILI, outpatient visits and hospitalisations for influenza-like illness; PI, pneumonia and influenza hospitalisations; u65, working age; u65, DM, working-age adults with diabetes mellitus; $65 p$, no DM, elderly adults without diabetes mellitus. in high-risk populations, resolving this uncertainty may require long overdue, randomised trials. ${ }^{31} 3335$

Acknowledgements The authors would like to acknowledge the support and expertise of Charles Burchill, Associate Director (Data Access), Manitoba Centre for Health Policy. This study was approved by the Health Information Privacy Committee of Manitoba (2011/2012-2016). The results and conclusions presented are those of the authors. No official endorsement by Manitoba Health is intended or should be inferred.

Contributors All authors contributed to the design and conception of the study. $\mathrm{DL}$ performed the data analysis and wrote the first draft of the article. All authors contributed to data interpretation and revisions. All authors have reviewed and approved the final draft.

Funding This work was supported by an open operating grant from the Canadian Institutes of Health Research (MOP-119316). DL is funded by MD/PhD studentships from CIHR and Alberta Innovates-Health Solutions (AIHS). DTE holds a CIHR New Investigator award and is an AlHS Population Health Investigator. SRM holds the Endowed Chair in Patient Health Management, supported by the Faculty of Medicine and Dentistry and the Faculty of Pharmacy and Pharmaceutical Sciences, University of Alberta, and is an AIHS Health Scholar. JAJ is an AIHS Senior Scholar and a Centennial Professor at the University of Alberta.

\section{Competing interests None.}

Ethics approval University of Manitoba Health Research Ethics Board.

Provenance and peer review Not commissioned; externally peer reviewed.

Open Access This is an Open Access article distributed in accordance with the Creative Commons Attribution Non Commercial (CC BY-NC 3.0) license, which permits others to distribute, remix, adapt, build upon this work non-commercially, and license their derivative works on different terms, provided the original work is properly cited and the use is non-commercial. See: http://creativecommons.org/ licenses/by-nc/3.0/

\section{REFERENCES}

1 Schanzer DL, Langley JM, Tam TWS. Co-morbidities associated with influenza-attributed mortality, 1994-2000, Canada. Vaccine 2008:26:4697-703.

2 National Advisory Committee on Immunizations. Statement on seasonal influenza vaccine for 2011-2012. Can Commun Dis Rep Wkly 2011:37:1-55.

3 Advisory Committee on Immunization Practices. Prevention and control of influenza with vaccines. Morb Mortal Wkly Rep 2010;59:1-62.

4 Smith SA, Poland GA. Use of influenza and pneumococcal vaccines in people with diabetes. Diabetes Care 2000;23:95-108.

5 American Diabetes Association. Standards of medical care in diabetes-2009. Diabetes Care 2009;32:S13-61.

6 Canadian Diabetes Association Clinical Practice Guidelines Expert Committee. Influenza and pneumococcal immunizations. Can J Diabetes 2008;32:S86-7.

7 Nichol KL, Zimmerman R. Generalist and subspecialist physicians' knowledge, attitudes, and practices regarding influenza and pneumococcal vaccinations for elderly and other high-risk patients: a nationwide survey. Arch Intern Med 2001;161:2702-8.

8 Szilagyi PG, Shone LP, Barth $R$, et al. Physician practices and attitudes regarding adult immunizations. Prev Med 2005;40:152-61.

9 Hak E, Nordin J, Wei F, et al. Influence of high-risk medical conditions on the effectiveness of influenza vaccination among elderly members of 3 large managed-care organizations. Clin Infect Dis 2002;35:370-7.

10 Heymann AD, Shapiro Y, Chodick G, et al. Reduced hospitalizations and death associated with influenza vaccination among patients with and without diabetes. Diabetes Care 2004:27:2581-4. 
11 Colquhoun AJ, Nicholson KG, Botha JL, et al. Effectiveness of influenza vaccine in reducing hospital admissions in people with diabetes. Epidemiol Infect 1997:119:335-41.

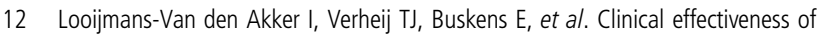
first and repeat influenza vaccination in adult and elderly diabetic patients. Diabetes Care 2006;29:1771-6.

13 Jefferson $T$, Rivetti $D$, Rivetti $A$, et al. Efficacy and effectiveness of influenza vaccines in elderly people: a systematic review. Lancet 2005;366:1165-74.

14 Nichol KL, Nordin JD, Nelson DB, et al. Effectiveness of influenza vaccine in the community-dwelling elderly. N Engl J Med 2007;357:1373-81.

15 Jackson LA, Jackson ML, Nelson JC, et al. Evidence of bias in estimates of influenza vaccine effectiveness in seniors. Int J Epidemiol 2006:35:337-44.

16 Manuel DG, Schultz SE. Health-related quality of life and health-adjusted life expectancy of people with diabetes in Ontario, Canada, 1996-1997. Diabetes Care 2004;27:407-14

17 Neuzil KM, Reed GW, Mitchel EF Jr., et al. Influenza-associated morbidity and mortality in young and middle-aged women. JAMA 1999;281:901-7.

18 Thompson WW, Shay DK, Weintraub E, et al. Influenza-associated hospitalizations in the United States. JAMA 2004;292:1333-40.

19 Schanzer DL, Langley JM, Tam TWS. Role of influenza and other respiratory viruses in admissions of adults to Canadian hospitals. Influenza Other Respi Viruses 2008;2:1-8.

20 Nelson JC, Jackson ML, Weiss NS, et al. New strategies are needed to improve the accuracy of influenza vaccine effectiveness estimates among seniors. J Clin Epidemiol 2009:62:687-94.

21 Manitoba Centre for Health Policy. Population Health Research Data Repository, Administrative Health Databases. Winnipeg, Manitoba: Manitoba Centre for Health Policy. 2011. http://www.umanitoba.ca/faculties/medicine/units/community_health_sciences/ departmental_units/mchp/resources/repository/health_admin.html (accessed 24 Jun 2011).

22 Hilderman T, Katz A, Derksen S, et al. Manitoba immunization study. Winnipeg, MB: Manitoba Centre for Health Policy, 2011:1-229.
23 Blanchard JF, Ludwig S, Wajda A, et al. Incidence and prevalence of diabetes in Manitoba, 1986-1991. Diabetes Care 1996;19:807-11.

24 Hottes TS, Skowronski DM, Hiebert B, et al. Influenza vaccine effectiveness in the elderly based on administrative databases: change in immunization habit as a marker for bias. PLOS ONE 2011;6:e22618.

25 Belongia E, Irving S, Waring S, et al. Clinical characteristics and 30-day outcomes for influenza A 2009 (H1N1), 2008-2009 (H1N1), and 2007-2008 (H3N2) infections. JAMA 2010;304:1091-8.

26 Tsui FC, Wagner MM, Dato V, et al. Value of ICD-9 coded chief complaints for detection of epidemics. Proc AMIA Symp 2001:711-15.

27 Krieger N. Overcoming the absence of socioeconomic data in medical records: validation and application of a census-based methodology. Am J Public Health 1992;82:703-10.

28 Reid RJ, MacWilliam L, Verhulst L, et al. Performance of the ACG case-mix system in two Canadian provinces. Med Care 2001;39:86-99.

29 Sander B, Kwong JC, Bauch CT, et al. Economic appraisal of Ontario's universal influenza immunization program: a cost-utility analysis. PLoS Med 2010; 7:e1000256.

30 Jefferson T, Di Pietrantonj C. Inactivated influenza vaccines in the elderly-are you sure? Lancet 2007:370:1199-200.

31 Eurich DT, Marrie TJ, Johnstone J, et al. Mortality reduction with influenza vaccine in patients with pneumonia outside "flu" season: Pleiotropic benefits or residual confounding? Am J Respir Crit Care Med 2008;178:527-33.

32 Jackson LA, Nelson JC, Benson P, et al. Functional status is a confounder of the association of influenza vaccine and risk of all cause mortality in seniors. Int $J$ Epidemiol 2006;35:345-52.

33 Jefferson T. Influenza vaccination: policy versus evidence. BMJ 2006; 333:912-15.

34 Jefferson T, Di Pietrantonj $C$, Rivetti $A$, et al. Vaccines for preventing influenza in healthy adults. Cochrane Libr 2010:1-119.

35 Simonsen L, Viboud C, Taylor RJ, et al. Influenza vaccination and mortality benefits: new insights, new opportunities. Vaccine 2009:27:6300-4. 